\title{
The Changes of Homocysteine Serum Level and Body Mass Index of Overweight Young Women after Eight Weeks of Pilates Exercise
}

\author{
Maliheh Mohammadian ${ }^{1}$, Majid Anvari ${ }^{1}$ and Firouzeh Dehghan ${ }^{2}$ \\ ${ }^{1}$ Department of Exercise Physiology, Iran \\ ${ }^{2}$ Department of Exercise Physiology, Faculty of Physical Education and Sport Sciences, Iran
}

Submission: November 09, 2018; Published: November 20, 2018

*Corresponding author: Firouzeh Dehghan, Department of Exercise Physiology, Faculty of Physical Education and Sport Sciences, Iran

Abstract

Introduction: Homocysteine is associated with microalbuminuria, which is a serious indicator of the risk factor of cardiovascular disease and also known to mediate heart attack, the risk of arterial artery problems such as atherosclerosis. The present research aimed to investigate the effect of eight weeks Pilates exercise on serum homocysteine level and body mass index among overweight young women.

Methods: 20 women who were eligible to take part in the study were selected from the volunteers and then divided into two groups of control and Pilates exercise group. In the basic level, BMI and also, after 12 hours of overnight fasting, the amount of homocysteine level was measured. Pilates exercise group participated in eight weeks of Pilates exercise ( 3 sessions per week). The control group was barred from regular physical activity. At the end of the eighth week, BMI and homocysteine protein and mRNA level of both groups were measured. T-test was used for comparing pre-test and post-test. Independent t-test was used for between-group comparison of indices in pre and post-test stages. $\mathrm{P}<0.005$ is considered significant difference.

Results: Findings of the present research indicates that eight weeks of Pilates exercise leads to a significant decrease in the level of homocysteine and $\mathrm{BMI}$ among overweight women $(\mathrm{P}=0.001)$. Also, the experimental group exercising Pilates had a lower serum homocysteine $(\mathrm{P}=0.004)$ and $\mathrm{BMI}(\mathrm{P}=0.001)$ compared to the control group or pretest. However, there was no significant relationship between $\mathrm{BMI}$ and serum homocysteine decrease as a result of Pilates exercise $(\mathrm{P} \leq 0.05)$.

Conclusion: Eight weeks of Pilates exercise results in a significant decrease in homocysteine and BMI amount in overweight young women. Keywords: Pilates; Women; Homocysteine; BMI

\section{Introduction}

The increasing trend of obesity is one of the most major public health concern and health related issues [1]. According to an epidemiologic study conducted in 199 countries around the world in 2008, 1.46 billion adults were overweight. The scope of the outbreak obesity is varying substantially between nations, largest rise in Oceania and the lowest trend was estimated in India [1]. In the USA, 34 percent of adults aged above 20 suffered from obesity in 2008. in addition, East Mediterranean countries estimated an increased by over $20 \%$ [2]. A review study indicated that obesity reached an alarming level in all ages of the East Mediterranean countries. the spread development of obesity has been ranged from 25 to 81.9 percent among adults [3]. In the same vein, a research of systemic review has conducted a study regarding the effect of BMI on cardiovascular diseases which indicated that each 5 unit raised in BMI increases the chances of heart problems by 29 percent [4].
Homocysteine is considered to be associated with microalbuminuria, which is a serious indicator of the risk factor of future cardiovascular disease. Homocysteine is also known to mediate heart attack, whenever its level raises, the risk of arterial artery problems such as atherosclerosis would increase [5,6]. It is a phosphor containing amino acid which is formed during methionine metabolism [7]. Epidemiology studies revealed that high levels of homocysteine in blood plasma could be a risk factor for cardiovascular, heart attack and peripheral vascular diseases and it causes atherosclerosis through three ways of intra-arterial wall damage, interference in the blood-clotting factors, and the oxidation of low density lipoprotein [8]. The prevalence of hyper homo cysteinemia is estimated to be about 5 percent in the general population and 13 to 14 percent among patients with symptoms of atherosclerosis. However, these estimates are based on a cut above the 90th or 95th percentile of 
total homocysteine distribution in the general population $[7,9]$. Various surveys have shown that levels of this amino acid are at a high level in obese or overweight as well as those who do not have regular exercise. Yet, there is debate on the effects of physical activity on this factor [8].

The effect of stair climbing with moderate intensity exercise on cardio-respiratory Fitness, blood lipids, and serum homocysteine were examined among sedentary young women. This study showed that these exercises can favorably make some changes in homocysteine cardiovascular risk factors and blood lipids profiles of inactive young women [10]. Vincent also reported that the decrease in homocysteine level caused

Table 1: Anthropometric and demographics characteristics of the subjects.

\begin{tabular}{|c|c|c|c|c|}
\hline & \multicolumn{2}{|c|}{ Control group Mean \pm SEM } & \multicolumn{2}{|c|}{ Pilates Training group Mean \pm SEM } \\
\hline & Pre-test & Post-test & Pre-test & Post-test \\
\hline Age (year) & $34.5 \pm 4.71$ & $34.5 \pm 4.71$ & $23.8 \pm 3.82$ & $23.8 \pm 3.82$ \\
\hline Height, $\mathrm{cm}$ & $163.3 \pm 3.85$ & $163.3 \pm 3.85$ & $166.4 \pm 4.12$ & $166.4 \pm 4.12$ \\
\hline Weight, cm & $73.6 \pm 2.1$ & $74.2 \pm 2.5$ & $75.4 \pm 3.4$ & $69.1 \pm 4.5$ \\
\hline Systolic blood pressure (mmHg) & $129.4 \pm 1.2$ & $129.6 \pm 1.9$ & $129.8 \pm 2.6$ & $129.1 \pm 1.3$ \\
\hline Diastolic blood pressure (mmHg) & $89.4 \pm 1.66$ & $90.1 \pm 2.34$ & $89.2 \pm 2.97$ & $87.1 \pm 2.55$ \\
\hline Heart rate $(\mathrm{bpm})$ & $99 \pm 4.6$ & $100 \pm 5.4$ & $89 \pm 7.3$ & $86 \pm 3.1$ \\
\hline
\end{tabular}

A collection of specialized sport activities affecting body and mind by using special equipment is called Pilates. It can increase power or endurance of whole body and even target the deepest muscles. Pilates exercises include effort for one's mental concentration on body muscles and how they function. Pilates exercise is named after its founder, Joseph Pilates, who developed a series of exercises in the 1920s to encourage physical and mental conditioning [14]. Strength, more body balanced, flexibility and core stability are emphasized in Pilates exercise to control of posture, movement, and breathing [15]. A survey in this domain showed that Pilates exercise among untrained women for 8 weeks leads to decreased serum creatine kinase, LDL, TG and Cholesterol. They also reported that Pilates Table 2: Results of dependent and independent t-test for homocysteine and BMI.

\begin{tabular}{|c|c|c|c|c|c|c|}
\hline Index & Group & Research stage & Mean and SD & In-group $P$ & Betwe & oup P \\
\hline \multirow{4}{*}{ Homocysteine (mmol/l) } & \multirow{2}{*}{ Pilates } & Pre test & $46.0 \pm 31.7$ & \multirow{2}{*}{001.0} & \multirow{2}{*}{ Pre test } & \multirow{2}{*}{717.0} \\
\hline & & Post test & $45.0 \pm 51.6$ & & & \\
\hline & \multirow{2}{*}{ Control } & Pre test & $61.0 \pm 22.7$ & \multirow{2}{*}{121.0} & \multirow{2}{*}{ Pre test } & \multirow{2}{*}{004.0} \\
\hline & & Post test & $7.0 \pm 38.7$ & & & \\
\hline \multirow{3}{*}{ Body mass index $\left(\mathrm{kg} / \mathrm{m}^{2}\right)$} & \multirow{2}{*}{ Pilates } & Pre test & $4.0 \pm 95.26$ & \multirow{2}{*}{001.0} & \multirow{2}{*}{ Pre test } & \multirow{2}{*}{7340.} \\
\hline & & Post test & $45.0 \pm 67.25$ & & & \\
\hline & Control & Pre test & $0.37 \pm 1.27$ & 001.0 & Pre test & 001.0 \\
\hline
\end{tabular}

\section{Participation and Method}

\section{Subject recruitment}

The study involved 20 overweight women whose BMI was above 25 from "Tandorosti gym" located in Tehran, Iran. The volunteers had the required features for participation in this project, including; no cardiovascular disease, not consuming by resistive exercises among inactive elderly people in aged of $60 \_80$ [11]. Moreover, no change in homocysteine level had been reported among 6 inactive men who participated in a walking activity with low intensity exercise [12]. In addition, another study showed that homocysteine concentration does not lead to significant changes in sub maximal exercise. Hence, the training intensity, sex and age are the factors affecting the above index [13]. Nevertheless, level of participation and different levels of interest in continuing exercise are the most important keys to reduce weight in overweight population although it may be exhausting. Therefore, doing sport activity such as Pilates can have a prominent role in increasing their interest in exercise (Table 1). increases HDL among these people [16]. Moreover, it has been investigated the effect of 24 weeks of Pilates exercise among elderly women and reported that this activity culminates in increased bone strength and decreased body lipid mass [17]. Nonetheless, there is no conclusive result about the effect of Pilates on homocysteine level and it has not been clearly identified whether the intensity employed in Pilates exercises has any effect on the amount of homocysteine of overweight women. Hence, the present research designed to investigate the effect of 8 weeks of Pilates exercise on protein and mRNA level of serum homocysteine and BMI among overweight young women (Table 2).

special medicine, no smoking, not having a regular exercise. Physiologic characteristics of volunteers including height, weight, age, BMI, heart rate, systolic and diastolic blood pressure were recorded. Participations were well informed about the study prior to the experiment and written consent was obtained from them. A double-blind study method was applied, and the participants were randomly assigned into 2 groups of 10; (1) 
control and (2) Pilates exercise groups. Pilates exercise group performed Pilates exercise 3 times per week for 8 weeks. It contains movements which engaged abdominal muscles, hips, waist, legs and shoulder belt and it was performed on a mat without any specific equipment in three conditions of sitting, standing and lying down. During this period, the control group was also barred from participating in regular physical activity. Prior the exercise protocol and at the end of eighth weeks, BMI was recorded, and blood sample was collected to measure protein or mRNA level of homocysteine. All procedures involving experiments were carried out in strict accordance of the United States Institute of Research guidelines and approved by the Medical Centre Board of Tehran University (Table 3).

Table 3: Relationship between body mass index and homocysteine level in Pilate's group.

\begin{tabular}{|c|c|c|c|c|c|}
\hline \multicolumn{1}{|c|}{ Index } & Group & stages & $\mathbf{r}$ & $\begin{array}{c}\text { Beta } \\
\text { Coefficient }\end{array}$ & P \\
\hline \multirow{2}{*}{$\begin{array}{c}\text { Relationship } \\
\text { Between BMI \& } \\
\text { Homocysteine }\end{array}$} & Pilates & Pre test & 120. & 346.0 & 327.0 \\
\cline { 3 - 6 } & Control & Post test & 03.0 & 172.0 & 634.0 \\
\cline { 3 - 6 } & & Pre test & 001.0 & 038.0 & 918.0 \\
\cline { 3 - 6 } & Post test & 012.0 & 111.0 & 76.0 \\
\hline
\end{tabular}

\section{Method of body mass index measurement}

The body mass index was calculated by measuring height in meters, weight in kilograms and putting them in the following formula:

Height $(\mathrm{m})^{2} /$ weight (in kilograms) = body mass index

\section{Blood Sample Collection}

Blood samples were collected at 24 hours before the pilates exercise and 24 hours after the last exercise session of 8 weeks training in fasting state through the elbow antecubital vein of all subjects for measurement of homocysteine mRNA and protein expressions.

\section{Measurement of Serum Homocysteine protein}

The level of serum homocysteine protein was measured by homocysteine measurement Elisa kit (Axis-shield diagonistmade in Germany). ELISA was performed according to the manufacturer's instructions. The absorbance for homocysteine was determined by using a microplate reader (iMark; Bio - Rad, Hercules, CA, USA) at a wavelength of $450 \mathrm{~nm}$. A set of standard serial dilutions of known concentrations of homocysteine were provided by the manufacturer and were used to construct a standard curve in order to determine the homocysteine levels. Homocysteine which was attached to protein was changed to free homocysteine and then it was changed to S-adenosyl L homocysteine (Figure 1).

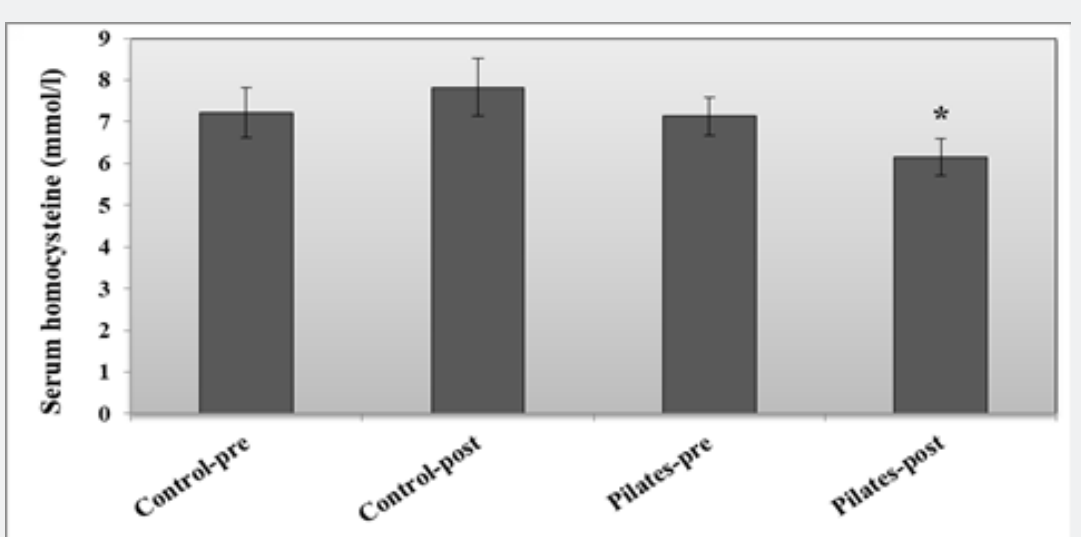

Figure 1: Serum homocysteine changes in control and Pilates exercise groups.

RNA purification and mRNA Expression Analysis by Real Time PCR (qPCR)

QIA amp RNA Blood Mini Kit (Qiagen, Germany) was used to isolate total cellular RNA from fresh whole blood. The concentration and purification of isolated RNA were evaluated by 260/280 UV absorption ratios (Gene Quant 1300, UK). Specific amplification fragments of DNA/RNA, Two-step Real time qPCR (quantitative Polymerase Chain Reaction) technique was used to calculate gene expression during the PCR amplification process with application of TaqMan reagent. This method was able to detect small differences between samples compared to other methods [18]. All reagents including probes and primers were obtained from Applied Biosystems, USA. TaqMan probe (known as fluorogenic $5^{\prime}$ nuclease) was chosen to perform qPCR. This probe has a sensitivity of $100 \%$ and a specificity of $96.67 \%$ [19] and is capable of detecting as few as 50 copies of RNA/ml and as low as 5-10 molecules [20].

\section{Primers were designed by the same company for homocysteine targets}

MRT: Hs01090026_m1; Lot no: 4351372, amplifies 61 bp segment from the whole mRNA length of $10558 \mathrm{bp}$. Beta Actin and GAPDH were used as reference genes. All amplification experiments were done in 3 biological replicates. Amplification program include 15 minutes at $48^{\circ} \mathrm{C}$ (reverse transcriptase), 10 minutes at $95{ }^{\circ} \mathrm{C}$ activation of ampli Taq gold DNA polymerase, denaturation at $95{ }^{\circ} \mathrm{C}$ for 15 second and annealing at $60{ }^{\circ} \mathrm{C}$ for 1 minute. Denaturation and annealing steps were performed for 40 cycles. Step-One Plus real time PCR machine, TaqMan Fast 
Advanced Master Mix and assays were purchased from Applied Biosystems, USA. The fold changes of each target per average of ACTB were calculated and considered as mRNA expression levels of the target gene. Data was analyzed according to Comparative Statistical method
Ct $(2-\Delta \Delta \mathrm{Ct})$ method, where amplification of the target and the reference genes were measured in the sample and reference [18].

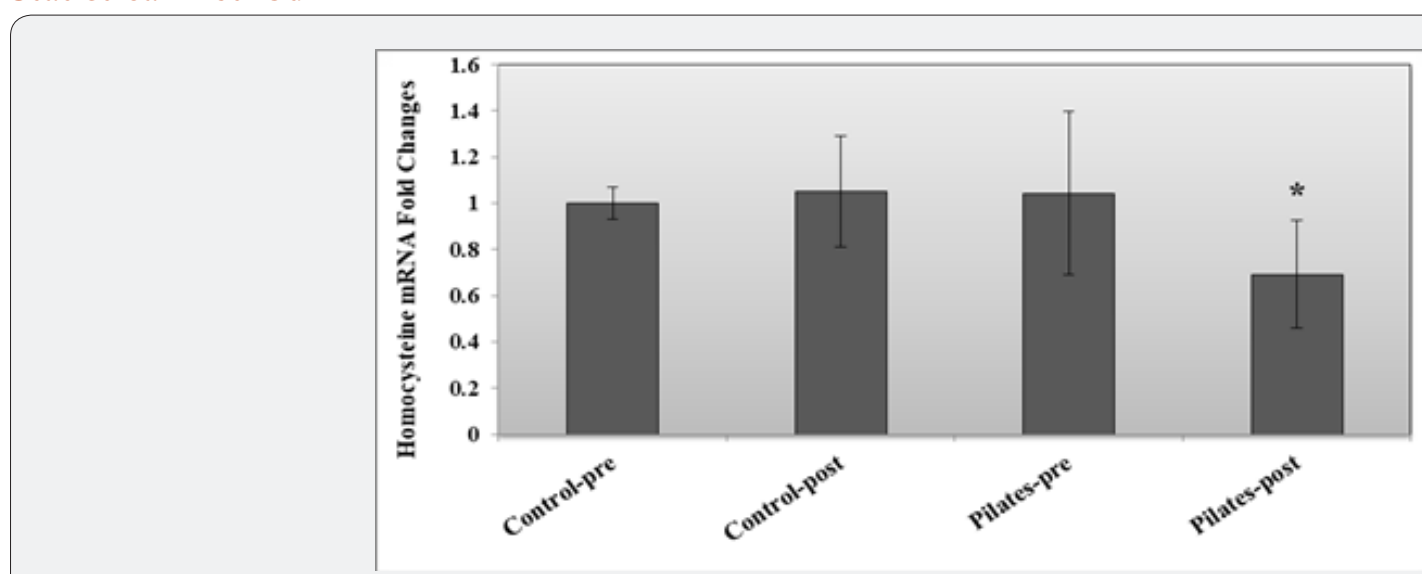

Figure 2: Homocysteine mRNA fold changes in control and Pilates exercise groups.

In this study, the Kolmogorov - Smirnov was used for the normal distribution of data as well as t-test (paired) for comparing pre-test and post-test stages within each group. Independent t-test was used for between-group comparison of indices in pre- and post-test stages. Pearson's coefficient and linear regression were used to examine the association between indices. All data in significance level of $05.0 \geq \mathrm{P}$ were examined using SPSS version 21 (Chicago, America) (Figure 2).

\section{Results}

\section{BMI}

Findings of this research show that 8 weeks Pilates exercise leads to a significant decreased of BMI among overweight women $(\mathrm{P}=0.001)$.

\section{Homocysteine protein expression quantification}

The findings indicate that homocysteine protein expression levels were significantly increased after 8 weeks Pilates exercise among overweight women compared to control group or pretest $(\mathrm{P}=0.001)$.

\section{Homocysteine mRNA expression level}

The results also indicate that homocysteine mRNA expression levels were significantly increased after 8 weeks Pilates exercise among overweight women compared to control group or pretest $(\mathrm{P}=0.0001)$. However, there was no significant change in the amount of these indices in the control group $(\mathrm{P} \leq 0.05)$. Also, there was no significant difference between the Pilates exercise group and the control group in pre-test stage regarding the homocysteine $(\mathrm{P}=0.004)$ and $\mathrm{BMI}(\mathrm{P}=0.001)$ level.

\section{Discussion and Conclusion}

This study reports a significant change in homocysteine level among overweight women after eight weeks of Pilates exercise. Although the comparison of two groups in the pre and post-test stages showed that the Pilates group had a lower level of homocysteine in the post-test stage compare to pre-test or control group, there was no significant change in the control group ( $\mathrm{P}=0.004)$. A study investigated the effect of aerobic exercise on homocysteine level among overweight women which suffered from polycystic ovary syndrome showed that a 6-week aerobic exercise caused a significant decrease in the level of homocysteine [21]. In addition, similar study reported findings in young untrained women [10]. On the other hand, Di Santolo et al, investigated the relationship between recreational sports and homocysteine level among young women and found no significant change in the level of homocysteine [22].

The effect of two types of exercise on homocysteine level have been examined, as well as other cardiovascular diseases risk factors. It was revealed that a 12 -week aerobic and resistive exercise does not make any significant change on the level of homocysteine, lipid profile and maximal aerobic power [23]. Furthermore, Bambaeichi et al, investigated the effect of increasing aerobic exercise on homocysteine level in young men and reported that the level of homocysteine did not have a significant change in the experimental group [24]. Various factors such as; intensity, type, or length of activity, gender or age of the participants have been considered to be effective on the divergent findings of the researchers. However, the effect of exercise on homocysteine can be explored from different aspects. During doing physical activity or recovery, amino acids more likely play an important role in anaplerotic functions sustaining the whole metabolic apparatus, as well as synthesis of other proteins, such as carnitine or melatonine. Increasing the energyreleasing reactions in the muscles; more induction in catabolism of amino acids such as methionine would be increasing. Also, regular sport activities increase renovation and repair muscle tissue by metabolic reactions require. 
Since methionine is an amino utilized in protein formation which starting material for numerous biochemical molecules. On the other hand, homocysteine is one of the critical biochemical junctures between methionine metabolism and the biosynthesis of the amino acids' cysteine and taurine, therefore decreasing methionine leads to homocysteine reduction [25]. There is this possibility that Pilates assists in decreasing homocysteine level and changing homocysteine to methionine leads to prevents its accumulation in the blood through increasing absorption of vitamins which are effective in homocysteine cycle especially group B vitamins (which decrease homocysteine during its menatbolosm) [26]. In addition, reduction of oxidative stress indices of regular exercise can also reduce levels of homocysteine [27]. Also, it is likely that insulin has an impact on homocysteine metabolism and its level through affecting activities of CBS, MTHFR enzymes, Systationine Gamma-lyase and betaine homocysteine methyltransferase [28]. Moreover, it seems that sport activities affect insulin role in decreasing homocysteine by reducing CRP and resistance to insulin [29].

The relationship between body composition and homocysteine is also of great importance. Although in the present study no significant relationship was found between them, BMI totally decreased with homocysteine reduction in Pilates group. The relationship between body composition and homocysteine have been investigated among Korean men and women in aged of 30 to 55 which had high homocysteine level. Findings of their study revealed that increase in total body fat content and decrease in LBM have a significant relationship with increased homocysteine. They reported that decrease in LBM is a suitable index for predicting homocysteine increase in different people [30]. Our findings showed that 8 weeks of Pilates exercise causes a significant decrease in BMI level among young overweight women. However, this change was not considered significant in the control group. In this domain, some consistent and contradictory studies can be mentioned. A 4 week of Pilates exercise on body composition have assessed in young girls. They showed that BMI level, waist size and blood pressure significantly decreased after 4 weeks of Pilates exercise [31]. Another study also explored the effect of two sport activities on indices of cardiovascular patients' body composition. They declared that BMI level and waist-to-hip ratio significantly decreased compared to pre-test [23]. Alternatively, 5-week Pilates exercise on trunk power, endurance and flexibility among low active adult women had no any significant change in BMI level [32].

Furthermore, no significant change also caused after doing 8 weeks Pilates exercise on fitness indices among low-active women [33]. Similarly, Cakmakçi et al found no significant change of BMI as a result of 8 weeks of Pilates exercise among obese women [34]. It seems as if the amount of subcutaneous fat, exercise intensity and the amount of nutrition control of the participants are among the influential factors with contradictory findings. Different factors can be pointed out regarding the effective mechanisms on Pilates exercise. A negative relationship was reported between body composition and the level of $\mathrm{VO}_{2}$ max [35]. It appears that sport activity can be effective in decreasing suitable BMI through increasing Lipoprotein Lipaz enzyme, fat tissue, blood flow, active muscles flow, and expanding the activity of hormones effective in metabolism [36-38]. In the similar vein, it has been reported a significant increase in aerobic power as a result of 8 weeks of Pilates exercise among obese women [39]. In conclusion, findings of this study showed that eight weeks of aerobic exercise significantly decreased the amount of homocysteine serum and body mass index in overweight young women. However, despite BMI level changes caused by Pilates, it seems that BMI decrease is not the major and effective factor on homocysteine decrease among overweight women. Probably there are other factors in this domain which have not been measured in this research. It is considered as the limitation of this study and should be taken into consideration in future researches.

\section{References}

1. Finucane MM, Stevens GA, Cowan MJ, Danaei G, Lin JK, et al. (2011) National, regional, and global trends in body-mass index since 1980: systematic analysis of health examination surveys and epidemiological studies with 960 country-years and 9.1 million participants. The Lancet 377(9765): 557-567.

2. Ogden CL, Yanovski SZ, Carroll MD, Flegal KM (2007) The epidemiology of obesity. Gastroenterology 132(6): 2087-2102.

3. Musaiger AO (2011) Overweight and Obesity in Eastern Mediterranean Region: Prevalence and Possible Causes. Journal of obesity 2011(6): 407237.

4. Bogers RP, Bemelmans WJ, Hoogenveen RT, Boshuizen HC, Woodward $M$, et al. (2007) Association of overweight with increased risk of coronary heart disease partly independent of blood pressure and cholesterol levels: a meta-analysis of 21 cohort studies including more than 300000 persons. Archives of internal medicine 167(16): 17201728.

5. Dankner R, Chetrit A, Dror GK, Sela BA (2007) Physical activity is inversely associated with total homocysteine levels, independent of C677T MTHFR genotype and plasma B vitamins Age 29(4): 219-227.

6. Unt E, Zilmer K, Mägi A, Kullisaar T, Kairane C, et al. (2008) Homocysteine status in former top-level male athletes: possible effect of physical activity and physical fitness. Scandinavian journal of medicine \& science in sports 18(3): 360-366.

7. McCully KS (1969) Vascular pathology of homocysteinemia: implications for the pathogenesis of arteriosclerosis. The American journal of pathology 56(1): 111-128.

8. Hrnciar J, Gabor D, Hrnciarova M, Okapcova J, Szentiványi M, et al. (1999) Relation between cytokines (TNF-alpha, IL-1 and 6) and homocysteine in android obesity and the phenomenon of insulin resistance syndromes. Vnitrni lekarstvi 45(1): 11-16.

9. Stampfer MJ, Malinow MR, Willett WC, Newcomer LM, Upson B, et al. (1992) A prospective study of plasma homocyst (e) ine and risk of myocardial infarction in US physicians. Jama 268(7): 877-881.

10. Boreham C, Kennedy R, Murphy M, Tully M, Wallace W, et al. (2005) Training effects of short bouts of stair climbing on cardiorespiratory fitness, blood lipids, and homocysteine in sedentary young women. British journal of sports medicine 39(9): 590-593. 
11. Vincent KR, Braith RW, Bottiglieri T, Vincent HK, Lowenthal DT (2003) Homocysteine and lipoprotein levels following resistance training in older adults. Preventive cardiology 6(4): 197-203.

12. Cooper A, Kendrick A, Stansbie D, Sargent D, West J (2000) Plasma Homocysteine in Sedentary Men: Influence of Moderately Intense Exercise. Journal of Cardiopulmonary Rehabilitation and Prevention 20(6): 394.

13. Gelecek N, Teoman N, Ozdirenc M, Pınar L, Akan P, et al. (2007) Influences of acute and chronic aerobic exercise on the plasma homocysteine level. Annals of Nutrition and Metabolism 51(1): 53-58.

14. Wells C, Kolt GS, Marshall P, Hill B, Bialocerkowski A (2013) Effectiveness of Pilates exercise in treating people with chronic low back pain: a systematic review of systematic reviews. BMC medical research methodology 13: 7.

15. Wells C, Kolt GS, Bialocerkowski A (2012) Defining Pilates exercise: A systematic review. Complementary therapies in medicine 20(4): 253262 .

16. Kim H-J, Kim J, Kim CS (2014) The effects of pilates exercise on lipid metabolism and inflammatory cytokines mRNA expression in female undergraduates. Journal of Exercise Nutrition \& Biochemistry 18(3) 267-275.

17. Ruiz Montero PJ, Castillo Rodriguez A, Mikalački M, Nebojsa Č, Korovljev D (2014) 24-weeks Pilates-aerobic and educative training to improve body fat mass in elderly Serbian women. Clinical interventions in aging 9: 243 .

18. Wong ML, Medrano JF (2005) Real-time PCR for mRNA quantitation. Biotechniques 39(1): 75-85.

19. Tsai YL, Wang HTT, Chang HFG, Tsai CF, Lin CK, etal. (2012) Development of TaqMan Probe-Based Insulated Isothermal PCR (iiPCR) for Sensitive and Specific On-Site Pathogen Detection. Plos one 7(9): e45278.

20. Hofmann Lehmann R, Williams AL, Swenerton RK, Li PL, Rasmussen RA, et al. (2002) Quantitation of simian cytokine and beta-chemokine mRNAs, using real-time reverse transcriptase-polymerase chain reaction: variations in expression during chronic primate lentivirus infection. AIDS research and human retroviruses 18(9): 627-639.

21. Randeva HS, Lewandowski KC, Drzewoski JZ, Brooke Wavell K, 0 callaghan C, et al. (2002) Exercise decreases plasma total homocysteine in overweight young women with polycystic ovary syndrome. The Journal of Clinical Endocrinology \& Metabolism 87(10): 4496-4501.

22. Di Santolo M, Banfi G, Stel G, Cauci S (2009) Association of recreational physical activity with homocysteine, folate and lipid markers in young women. European journal of applied physiology 105(1): 111-118.

23. Subaşı SS, Gelecek N, Aksakoğlu G, Örmen M (2012) Effects of two different exercise trainings on plasma homocysteine levels and other cardiovascular disease risks. Turkish Journal of Biochemistry/Turk Biyokimya Dergisi 37(3).

24. Bambaeichi E, Najari MA, Barjasteh B (2010) Influence of incremental aerobic exercise on homocysteine level in young males. British Journal of Sports Medicine 44(Suppl 1): i21-i22.

25. Miller AL (2003) The methionine-homocysteine cycle and its effects on cognitive diseases. (Homocysteine \& Cognitive). Alternative Medicine Review 8(1): 7-20.
26. Hamedinia M, Haghighi A, Ravasi A (2009) The effect of aerobic training on inflammatory markers of cardiovascular disease risk in obese men. World J Sport Sci 2(1): 07-12.

27. Hrncic D, Rasic Markovic A, Lekovic J, Krstic D, Colovic M, et al. (2014) Exercise decreases susceptibility to homocysteine seizures: the role of oxidative stress. International journal of sports medicine 35(07): 544550 .

28. Emoto M, Kanda H, Shoji T, Kawagishi T, Komatsu M, et al. (2001) Impact of insulin resistance and nephropathy on homocysteine in type 2 diabetes. Diabetes Care 24(3): 533-538.

29. Guthrie J, Clark M, Dennerstein L, Burger H (2005) Serum C-reactive protein and plasma homocysteine levels are associated with hormone therapy use and other factors: a population-based study of middleaged Australian-born women. Climacteric 8(3): 263-270.

30. Park SB, Georgiades A (2013) Changes in body composition predict homocysteine changes and hyperhomocysteinemia in Korea. Journal of Korean medical science 28(7): 1015-1020.

31. Jago R, Jonker ML, Missaghian M, Baranowski T (2006) Effect of 4 weeks of Pilates on the body composition of young girls. Preventive medicine 42(3): 177-180.

32. Sekendiz B, Altun Ö, Korkusuz F, Akın S (2007) Effects of Pilates exercise on trunk strength, endurance and flexibility in sedentary adult females. Journal of bodywork and movement therapies 11(4): 318-326.

33. Rogers K, Gibson AL (2009) Eight-week traditional mat Pilates training-program effects on adult fitness characteristics. Research quarterly for exercise and sport 80(3): 569-574.

34. Cakmakçi O (2011) The Effect of 8 Week Plates Exercise on Body Composition in Obese Women. Collegium antropologicum 35(4): 1045-1050.

35. Slinger J, Verstappen F, Van Breda E, Kuipers H (2006) The effect of body builds and BMI on aerobic test performance in school children (10-15 years). Journal of sports science \& medicine 5(4): 699-706.

36. Després JP, Couillard C, Gagnon J, Bergeron J, Leon AS, et al. (2000) Race, visceral adipose tissue, plasma lipids, and lipoprotein lipase activity in men and women. Arteriosclerosis, thrombosis, and vascular biology 20(8): 1932-1938.

37. Marandi SM, Abadi NGB, Esfarjani F, Mojtahedi H, Ghasemi G (2013) Effects of intensity of aerobics on body composition and blood lipid profile in obese/overweight females. International journal of preventive medicine 4(Suppl 1): S118-S125.

38. Daley A, MacArthur C, Stokes Lampard H, McManus R, Wilson S, et al (2007) Exercise participation, body mass index, and health-related quality of life in women of menopausal age. Br J Gen Pract 57(535): 130-135.

39. Ali ZO, Esfarjani F, Bambaeichi E, Marandi M (2010) The effects of Pilates exercise on blood pressure and selective physical fitness components in sedentary overweight females. British Journal of Sports Medicine 44(Suppl 1): i28-i28. 
(C) (1) This work is licensed under Creative Commons Attribution 4.0 License

DOI: 10.19080/JPFMTS.2018.05.555671

\section{Your next submission with Juniper Publishers} will reach you the below assets

- Quality Editorial service

- Swift Peer Review

- Reprints availability

- E-prints Service

- Manuscript Podcast for convenient understanding

- Global attainment for your research

- Manuscript accessibility in different formats ( Pdf, E-pub, Full Text, Audio)

- Unceasing customer service

Track the below URL for one-step submission https://juniperpublishers.com/online-submission.php 